\title{
An Analysis of the Gear Meshing Characteristics of the Main Planetary Gear Trains of Helicopters Undergoing Shafting Position Changes
}

\author{
Li Xuejun $\mathbb{D}^{1},{ }^{1}$ Jiang Lingli $\mathbb{D},{ }^{1}$ Hua Dengrong, ${ }^{2}$ Yin Daoxuan, ${ }^{2}$ and Yang Dalian $\mathbb{D}^{2}$ \\ ${ }^{1}$ School of Mechatronic Engineering and Automation, Foshan University, Foshan 528000, China \\ ${ }^{2}$ Hunan Provincial Key Laboratory of Health Maintenance for Mechanical Equipment, Hunan University of Science and Technology, \\ Xiangtan, Hunan 411201, China \\ Correspondence should be addressed to Jiang Lingli; linlyjiang@163.com
}

Received 9 March 2021; Revised 20 June 2021; Accepted 2 July 2021; Published 31 July 2021

Academic Editor: Mohammad Tawfik

Copyright (c) $2021 \mathrm{Li}$ Xuejun et al. This is an open access article distributed under the Creative Commons Attribution License, which permits unrestricted use, distribution, and reproduction in any medium, provided the original work is properly cited.

\begin{abstract}
The complex three-shaft three-reducer structural designs of helicopter transmission systems are prone to changes in the relative positions of shafting under the conditions of main rotor and tail rotor loads. These changes will affect the transmission characteristics of the entire transmission system. In this study, the planetary gear trains of helicopters were examined. Due to the fact that these structures are considered to be the most representative structures of the main reducers of helicopters, they were selected as the study objects for the purpose of examining the meshing characteristics of planetary gear trains when the relative positions of the shafting changed due to the position changes of the main rotor shafts under variable load conditions. It was found that by embedding the comprehensive time-varying meshing stiffness values of the main rotor shafts at different positions, a dynamic model of the relative position changes of the planetary gear trains could be established. Then, combined with the multibody dynamics software, the meshing characteristics of the sun gears, and the planetary gears, the planetary gears and the inner ring gears were simulated and analyzed under different inclinations and offsets of the shafting. The results obtained in this study revealed the following: (1) the average meshing force of the gears increased with the increases in the angle inclinations, and the meshing force between the sun gears and the planetary gears increased faster than the meshing force between the planetary gears and the inner ring gears. It was observed that during the changes in the shafting tilt positions, obvious side frequency signals had appeared around the peak of the meshing frequency in the spectrum. Then, with the continuous increases in the tilt position, the peak was gradually submerged; (2) the average meshing force of the gears increased with the increases in the offset, and the increasing trend of the meshing force between the sun gears and the planetary gears was similar to that observed between the planetary gears and the inner ring gears. It was found that when the shafting offset position changed, there were obvious first and second frequency doubling in the spectrum; (3) the mass center orbit radii of the sun gears increased with the increases in the shafting position changes, and the changes in the angular tilt position were found to have greater influencing effects on the mass center orbit radii of the sun gears than the changes in the offset positions. This study's research findings will provide a theoretical basis for future operational status monitoring of the main transmission systems of helicopters and are of major significance for improvements in the operational stability of helicopter transmission systems, which will potentially ensure safe and efficient operations.
\end{abstract}

\section{Introductions}

The transmission system of helicopters, including the main reducers, intermediate reducers, tail reducers, main rotor shafts, power transmission shafts, and tail transmission shafts (namely, "three shafts and three reducers"), is charac- terized by compact structures, lightweight, high process precision, high transmission power levels, and high reduction ratios. It is indispensable key components of helicopter design, transferring engine power to both the main rotors and tail rotors $[1,2]$. Due to lack of redundancy, helicopter transmission failure can lead to catastrophic accidents [3]. 
Therefore, condition monitoring for helicopter transmission has always been one of the most critical technologies to guarantee the integrity of the helicopters, enhance operational and personnel safety, and reduce the overall maintenance costs $[4,5]$. Over the past decades, health and usage monitoring systems (HUMS) have been developed and implemented in helicopters to monitor the health status for the main gearbox and other key components of transmissions, improving condition-based maintenance for helicopters [6, 7]. Meanwhile, a batch of fault diagnosis researches around the bearings and gears of the main gearbox emerged [8-10]. In fact, change in the relative position of the helicopter transmission shafting is one of the important reasons for the failure of bearings and gears.

It has been found that under load conditions of the main rotors and tail rotors, the three shafts and three reducers tend to be prone to changes in the relative positions of shafting. Considering the complex shafting structural designs of helicopters, any slight changes in the relative positions of shafting will lead to changes in the transmission characteristics of the entire transmission system, which will accelerate the wear of support bearings, shorten the service life of the bearings, and greatly impact the tooth surface friction at the gear meshing. As a result, vibration impacts will be produced which will negatively affect the performances of the transmission systems $[11,12]$. Due to the aforementioned tendencies, the transmission systems of helicopters may be subjected to additional excitation force, which will significantly reduce the working life of the transmission systems. This study considered to reveal the dynamic response characteristics of the helicopter shaft systems under changes in the relative position, which could potentially provide a theoretical basis for the failure mechanism analysis of the helicopter transmission, the operational status monitoring of the helicopter transmission systems, and furthermore, be of major significance for improving the operation stability of the helicopter transmission systems and ensuring safe and efficient operations.

Dynamic modeling is the first step for analyzing the dynamic response characteristics of the helicopter shaft systems under changes in the relative position. Chenxi et al. established a nonlinear dynamic model of helicopter transmission to measure the load sharing with dynamic mesh forces quantitatively [13]. Lyu et al. developed a physical model of helicopter transmission for sensor selection [14]. Zhang et al. established an integral node dynamic model of helicopter main gearbox combined with the finite element method and the lumped mass method [15]. Chen et al. applied the finite element method and the lumped mass method mixed to establish the overall multinode dynamic model of a four-stage helicopter main gearbox [16]. All of the above modeling methods can provide an important reference for the modeling of this research. Planetary gear sets are the major structures of the main transmission systems of helicopters. Researchers in China and internationally have completed many studies regarding the dynamic characteristics of planetary gear train systems. Liu et al. and Zhang et al. established a dynamic model of planetary gear trains and studied the vibration characteristics of gear systems

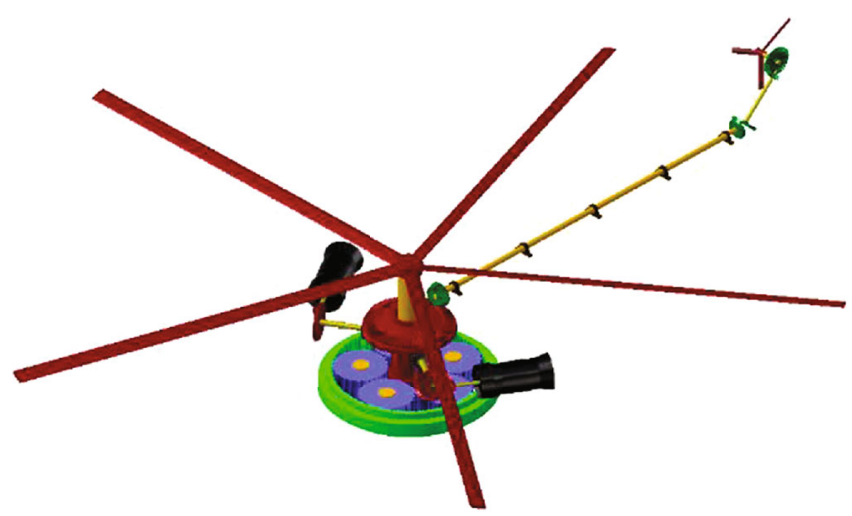

FIgure 1: The structure diagram of the study helicopter transmission systems.

$[17,18]$. Zou et al. and Ma et al. studied time-varying meshing stiffness values when sun gears became cracked and established a dynamic model for planetary gear trains $[19,20]$. Lei et al., Wei et al., and Han et al. established fault models of planetary gear trains: normal, cracked, and spalling, and analyzed their dynamic characteristics [21-23]. Parker and $\mathrm{Wu}$ mainly used a finite element method to analyze the vibration modes of planetary gear trains, focusing on the effects of such factors as meshing stiffness values and contact ratios on the suppression of system vibrations and noise [24]. In another related study, Chao et al., Liu et al., and Mbarek et al. analyzed and studied the dynamic characteristics and meshing stiffness of the planetary gear trains with tooth profile errors, cracks, and other faults [25-27]. This study found that the existing research studies had mainly focused on the dynamic response characteristics of planetary gear trains from the perspectives of backlash, timevarying meshing stiffness, transmission errors, local faults of the gears, and coupling faults [28-30]. In this study, the dynamic response characteristics of planetary gear trains were investigated from the perspective of changes in relative positions of shafting. The results obtained in this research investigation were considered as supplements for the continued improvements of the dynamics of helicopter transmission systems and gear systems.

\section{Dynamic Modeling of Main Planetary Gear Trains with Shafting Position Changes}

The position changes of shafting mainly affect the meshing stiffness of gears. In this study, the time-varying meshing stiffness values were used to map the position changes of the shafting. The structural characteristics of helicopter transmission systems were taken as the study objects, as shown in Figure 1.

The planetary gear trains of the main transmission systems consist of one sun gear, five planetary gears, and one inner ring gear. The inner ring gear is fixedly connected to the main reducer housing. The sun gears are the input ends and the planetary carriers which are fixedly connected with the main rotor shafts are the output ends. The gear parameters of a planetary gear train are shown in Table 1. 
TABLE 1: Gear parameters of the study planetary gear trains.

\begin{tabular}{lccccc}
\hline Gear & Num. of teeth & Outer module $(\mathrm{mm})$ & Pressure angle $\left(^{\circ}\right)$ & Spiral angle $\left(^{\circ}\right)$ & Face width $(\mathrm{mm})$ \\
\hline $\mathrm{Zs}$ & 62 & 8 & 20 & 0 & 300 \\
$\mathrm{Zr}$ & 83 & 8 & 20 & 0 & 320 \\
$\mathrm{Zc}$ & 228 & 8 & 20 & 0 & 350 \\
\hline
\end{tabular}
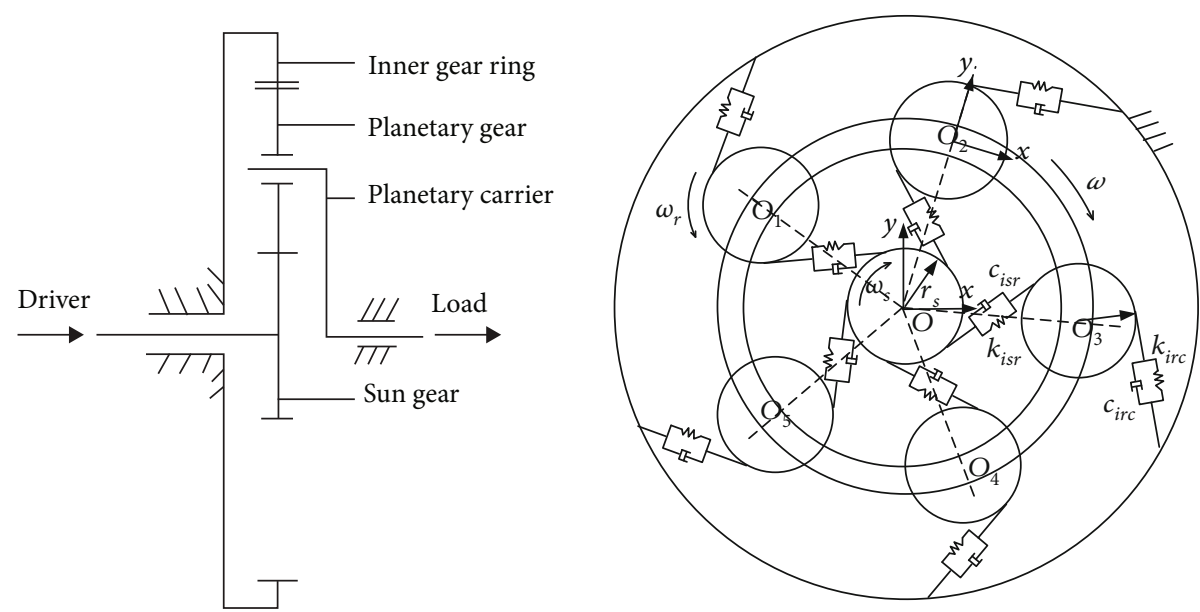

FIGURE 2: Dynamic theoretical model of the planetary gear trains.

\subsection{Dynamic Theoretical Model of the Planetary Gear Trains.} Helicopter planetary gear trains have the structural characteristics of long main rotor shafts and large load fluctuations. As a result, the main rotor shafts which join the planetary carriers are directly connected with the loads. Therefore, if the supports loosen, position changes may easily be caused. In the present study, a torsion model of a planetary gear train was established in order to examine the dynamic characteristics. It was possible to simplify the model into the dynamic model shown in Figure 2 according to the principles of gear meshing.

It was assumed that the centroid of each gear coincided with its geometric center. That is to say, there was no centroid offset, and the influencing effects of the friction between gears were ignored. Then, the system had a total of 21 degrees of freedom. In other words, the freedom of movement of the sun gear, planetary gear, and inner ring gear along the $x$ and $y$ directions were $x_{s}, y_{s}, x_{r i}, y_{r i}, x_{c}, y_{c}$; and the freedom of rotation between the sun gear, planetary gear, and inner ring gear was $\theta_{s}, \theta_{r i}, \theta_{c}$; and the generalized displacement matrix could be expressed as follows:

$$
q=\left\{x_{s} y_{s} x_{r i} y_{r i} x_{c} y_{c} \theta_{s} \theta_{r i} \theta_{c}\right\}^{T},
$$

where $i=(1,2 \cdots 5)$ represents the five planetary gears, respectively.

A fixed coordinate system was established at the center of the sun gear, and a dynamic coordinate system was established at the center of the planetary gear. The rotation speed of the dynamic coordinate system was the rotation speed of the planetary carrier $\omega$. Then, the projection of the relative displacement between the sun gear and planetary gears and between the planetary gear and inner ring gears along the direction of the meshing line was as follows:

$$
\begin{aligned}
& x_{n s r i}=r_{m r} \theta_{r i}-r_{m s} \theta_{s i}-e_{n}(t), \\
& x_{n r c i}=r_{m c} \theta_{c}-r_{m r} \theta_{r i}-e_{n}(t),
\end{aligned}
$$

where $r_{m s}, r_{m r}, r_{m c}$ are the base circle radii of the sun gear, planetary gear, and inner ring gear, respectively; and $e_{n}(t)$ indicates the static transmission error of the gear.

The meshing force of the normal gear between the sun gear and the planetary gears in planetary gear train $F_{n s i}$ and meshing force of the normal gear between the planetary gears and inner ring gear $F_{n r c i}$ were as follows:

$$
\begin{aligned}
& F_{n s r i}=k_{i s r}(t) x_{n s r i}+c_{s r m} x_{n s r i}^{\prime}, \\
& F_{n r c i}=k_{i r c}(t) x_{n r c i}+c_{r c m} x_{n r c i}^{\prime},
\end{aligned}
$$

where $k_{i s r}(t), k_{i r c}(t)$ are the time-varying meshing stiffness between the sun gear and the planetary gears and between the planetary gears and the inner ring gear, respectively; $x_{n s r i}, x_{n r c i}$ represents the vibration displacements between the sun gear and planetary gears and between the planetary gears and the inner ring gear along the direction of the meshing line, respectively; and $c_{s r m}, c_{r c m}$ indicate the damping coefficients between the sun gear and the planetary gears and between the planetary gears and the inner ring gear, respectively. 
Then, the dynamic equation of the system was obtained as follows:

$$
\left\{\begin{array}{l}
I_{s} \ddot{\theta}_{s}+r_{m s} \sum_{i=1}^{5} F_{n s r i}=T_{d}, \\
m_{s} \ddot{x}_{\mathrm{is}}+c_{s x} \dot{x}_{\mathrm{is}}+k_{s x} x_{\mathrm{is}}=F_{i s x}, \\
m_{s} \ddot{y}_{\mathrm{is}}+c_{s y} \dot{y}_{\mathrm{is}}+k_{s y} y_{\mathrm{is}}=F_{i s y}, \\
I_{r i} \ddot{\theta}_{r i}-r_{m r} F_{n s r i}+r_{m r} F_{n r c i}=0, \\
m_{r} \ddot{x}_{i r}+c_{r x} \dot{x}_{i r}+k_{r x} x_{i r}=F_{i r x}, \\
m_{r} \ddot{y}_{i r}+c_{r y} \dot{y}_{i r}+k_{r y} y_{i r}=F_{i r y}, \\
I_{c} \ddot{\theta}_{c}-r_{m c} \sum_{i=1}^{5} F_{n r c i}=T_{f}, \\
m_{c} \ddot{x_{i c}}+c_{c x} \dot{x}_{i c}+k_{c x} x_{i c}=F_{i c x}, \\
m_{c} \ddot{y}_{i c}+c_{c y} \dot{y}_{i c}+k_{c y} y_{i c}=F_{i c y},
\end{array}\right.
$$

where $m_{s}, m_{r}, m_{c}$ represent the masses of the sun gear, planetary gear, and inner ring gear, respectively; $I_{s}, I_{r}, I_{c}$ are the moments of inertia of the sun gear, planetary gear, and inner ring gear, respectively; $k_{v j}, c_{v j}(v=s, r, c ; j=x, y)$ denote the support stiffness and damping values of the sun gear, planetary gear, and inner ring gear along each coordinate axis, respectively; $\theta_{s}, \theta_{r}, \theta_{c}$ indicate the torsional displacements of the sun gear, planetary gear, and inner ring gear, respectively; $T_{d}, T_{f}$ are the driving torque of the driving gear and the load torque of the driven gear, respectively; and $i=(1,2 \cdots 5)$.

Therefore, Eq. (5) can be rewritten in the form of a matrix as follows:

$$
I \ddot{\theta}+C R^{2} \dot{\theta}+K(\mathrm{t}) R^{2} \theta=T,
$$

where $K(\mathrm{t})$ represents the stiffness matrix, and $C$ is the damping matrix.

In this study, the time-varying meshing stiffness $K^{\prime}(\mathrm{t})$ after the shafting position changes was used to represent the influencing effects of the shafting position changes on the meshing characteristics of the system. The dynamic theoretical model of the main planetary gear trains with shafting position changes was as follows:

$$
I \ddot{\theta}+C R^{2} \dot{\theta}+K^{\prime}(\mathrm{t}) R^{2} \theta=T .
$$

2.2. Calculations of the Time-Varying Meshing Stiffness Values Based on Ansys. During flight, the atmospheric circulations in different regions will vary, and the excitation loads on the main rotor shafts will also differ. Generally speaking, the wear amount of two individual support bearings will be different. In this study, compared with the original axis, the no. 2 bearing was offset by $e_{2}$ and the no. 1 bearing was offset by $e_{1}$. Therefore, when $e_{1}>e_{2}$, an inclination angle $\alpha$ was generated between the axis with the position change and the original axis, as shown in Figure 3. Consequently, due to the

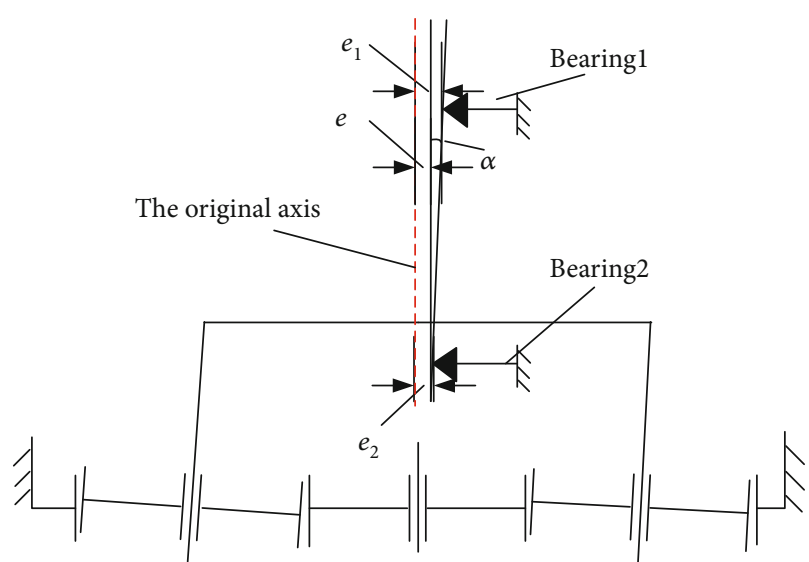

FIgURE 3: The theoretical analysis diagram of the shaft system undergoing shafting position changes.

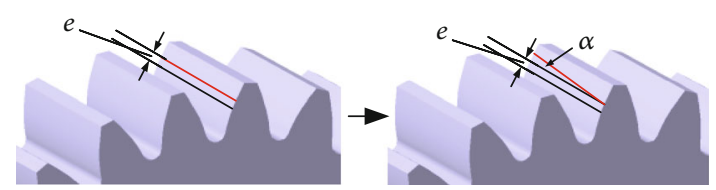

Figure 4: The changed meshing line of the gear.

change in the position, the meshing force of the planetary gear train experienced a malignant change during operation.

When the position of the main rotor shaft changed, the meshing line of the gear also changed accordingly, as illustrated in Figure 4.

Then, by taking one-quarter of the driving and driven gears, the meshing lines of the two gears were solved by concentrated force loading in the static module of the ANSYS workbench. Specifically, a 3D gear model built in CATIA was imported. In ANSYS, the material was set as $20 \mathrm{CrMnTi}$ (The modulus of elasticity is $20900 \mathrm{MPa}$. The Poisson's ratio is 0.3 . The density is $7860 \mathrm{~kg} / \mathrm{m}^{3}$.). Meshing adopted the "Mesh" module that comes with ANSYS workbench. The mesh size of the gear tooth area was controlled to $0.5 \mathrm{~mm}$, and the mesh size of the nongear tooth area was controlled to $1 \mathrm{~mm}$. The gear rotation pair used the "MPC184" unit, the contact area used the "CONTA174" and "TARGET170" units, and the gear pair main body used the "SOLID186" and "SOLID187" units. The meshing method of the tooth area adopted the "Tetrahedrons" and "Hex Dominant" division methods, and the nontooth area adopts the "Hex Dominant" division method. The corresponding points of the driving and driven gears were, respectively, loaded with constant forces of equal size in the direction perpendicular to the tangential direction of the gear teeth profiles in order to calculate their respective deformations one by one and obtain the total deformation of the two meshing teeth, as shown in Figure 5.

The meshing stiffness values of a single gear pair could then be calculated using a formula for calculating the comprehensive stiffness of a single gear pair as follows:

$$
k_{t}=\frac{F_{n}}{\delta_{z}+\delta_{c}},
$$




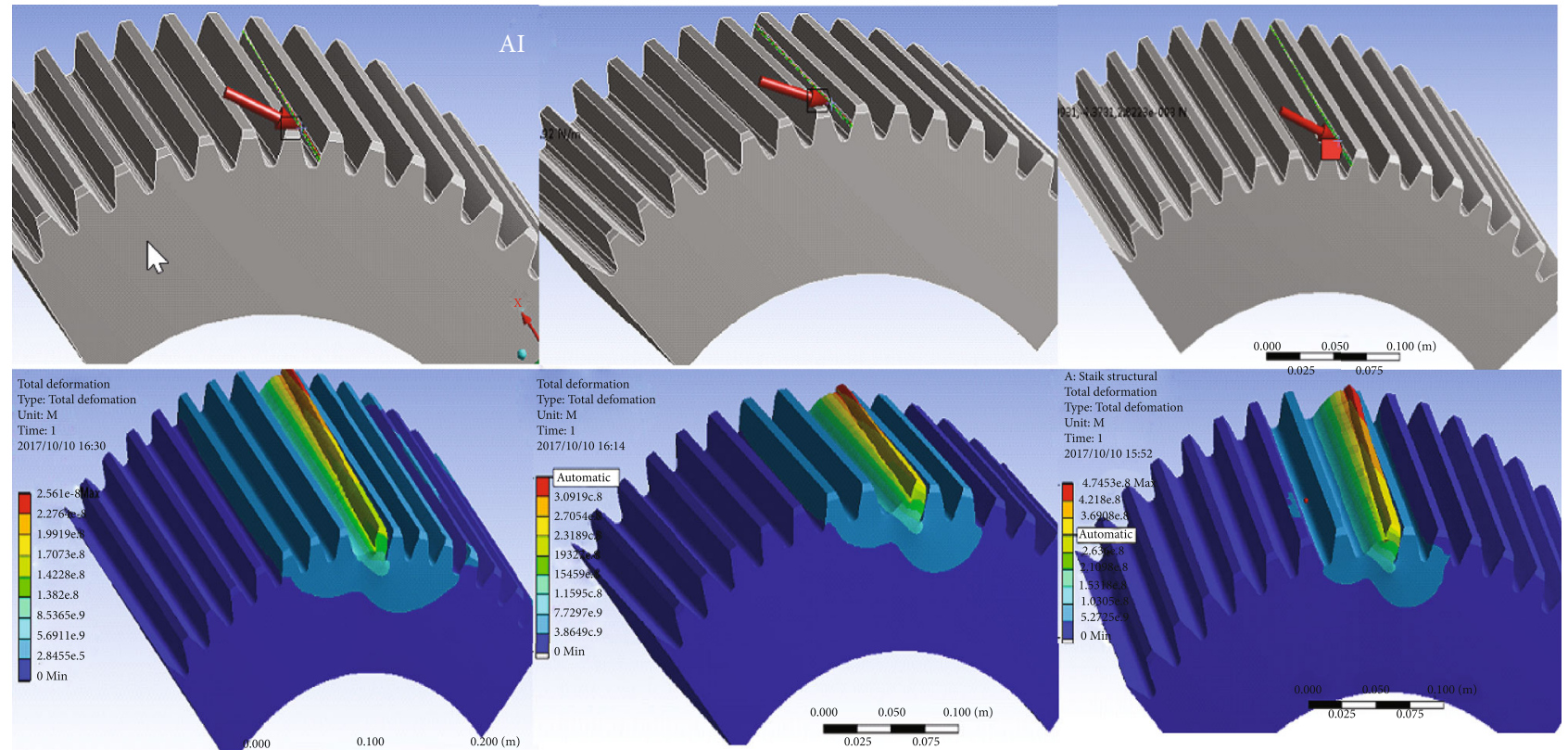

FIgURE 5: The loaded process diagram in ANSYS.

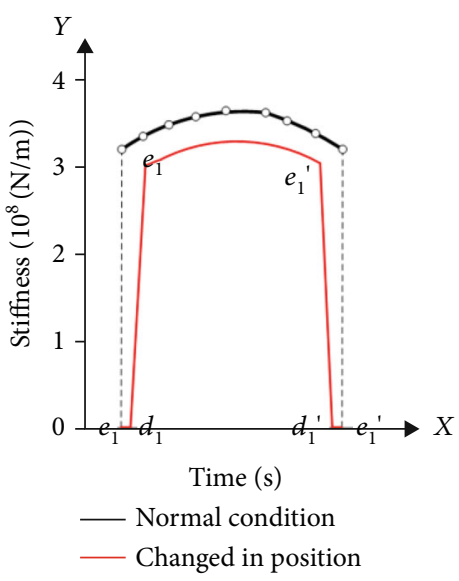

(a) The meshing stiffness curve of a single gear pair

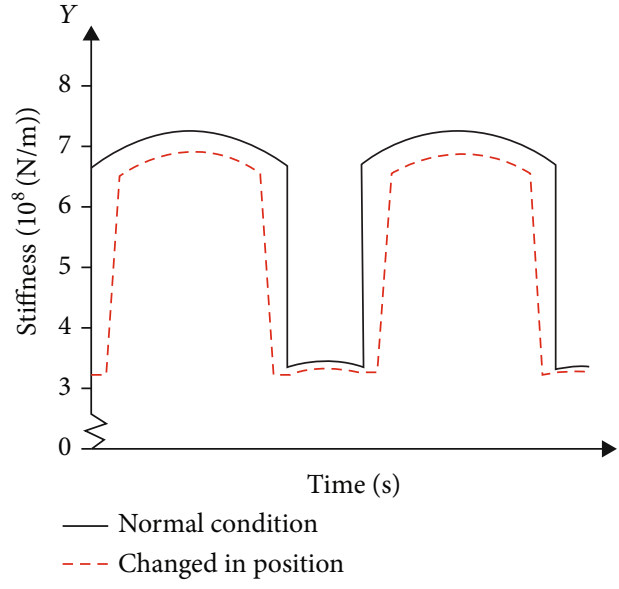

(b) The comprehensive meshing stiffness curve

Figure 6: The time-varying meshing stiffness curve.

where $F_{n}$ represents the static force being constantly loaded, not the true meshing force, and a smaller constant force is taken for the convenience of calculation; $n$ indicates the force at the meshing line when the gear is rotated by $1^{\circ}$; and $\delta_{z}+\delta_{c}$ is the sum of the deformations of the driving and driven gears.

The stress and deformation values of each point on the meshing line of the profile of the driving and driven gears at a certain angle were calculated in this study using ANSYS. The corresponding meshing stiffness was calculated according to Formula (9). It can be found from the analytic results that the meshing stiffness of each point decreased after the shafting positions changed, and the deformations under the same load were greater than those of the normal meshing gear teeth.
A pair of meshing points on the meshing line of the driving and driven gears was selected, and the time-varying meshing stiffness curve of a single gear pair was obtained by the curve fitting of the time-varying stiffness of the point, as shown in Figure 6(a). Therefore, the time-varying meshing stiffness curves of the other points could be obtained, respectively. Then, by considering the meshing coincidence degrees of the sun gear and planetary gear, the time-varying meshing stiffness of the other points was also determined. The comprehensive meshing stiffness curve is shown in Figure 6(b). It was found that by using the aforementioned method, the time-varying meshing stiffness between the sun gear and planetary gears and between the planetary gears and inner ring gear could be successfully calculated. 


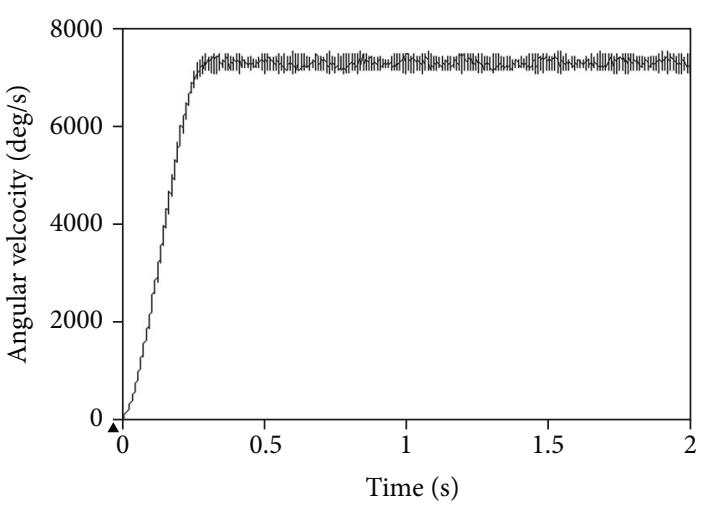

(a) Driving mode

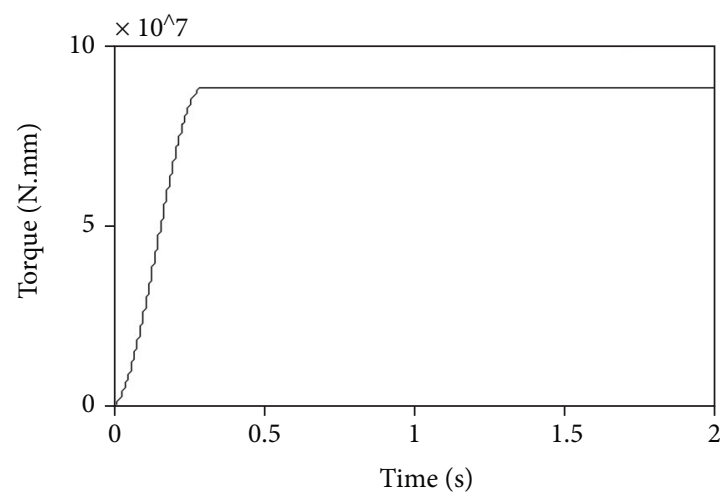

(b) Loading mode

FIGURE 7: Simulation parameter settings.

2.3. Dynamic Simulation Model Based on ADAMS. The corresponding simulation model was established according to the dynamic equation. The geometric changes of the axis positions were input in the CATIA 3D model, and the time-varying meshing stiffness caused by the shafting position changes was input in the ADAMS simulation model in the form of Fourier series expansion. The specific modeling process of the simulation model based on ADAMS was as follows.

2.3.1. Establishment of Rigid Body Model. The seamless connection software SimDesigner was used to import the 3D model into ADAMS. According to the structural characteristics of the main transmission system and the real movement process, corresponding driving and constraints were set to make the simulation model closer to the real movement process. The detail settings were as follows: (a) rotating pairs were set between the sun gear and the ground, the planet carrier and the ground, and the planet wheels and the planet carrier. (b) A fixed pair was set between the ring gear and the ground. (c) Contact pairs were set between the sun gear and the planetary gears and the planetary gears and the ring gear. The "Impact" module based on the impact function method was selected to realize the setting of the contact pair. The time-varying meshing stiffness was also input in this module. (d) A step function was applied on the sun gear as the driver, and a reverse step function was applied on the planet carrier as the load.

2.3.2. Flexibilization of Key Parts. The sun gear, planetary gears, and inner ring gear were, respectively, flexibly treated. The flexible processing work was completed in ANSYS. In the process of flexibilization of the sun gear and the planetary gears, the inner surfaces were used as the rigid area, and the two center points at the two ends of the inner hole were used as the connection points. In the process of flexibilization of the inner ring gear, the cylindrical surfaces were used as the rigid area, and the center points at the both ends of the inner hole were used as the connection points. Finally, the flexible parts were imported into the ADAMS to replace the original rigid parts to form a rigid-flexible coupling multibody dynamic model.

2.3.3. Implantation of the Time-Varying Meshing Stiffness. Taking the shaft offset of $0.3 \mathrm{~mm}$ and the inclination angle of $0.3^{\circ}$ as an example, according to the time-varying meshing stiffness calculation method described in 1.2, the timevarying meshing stiffness curve was obtained. Taking meshing stiffness between the sun gear and the planet gears as an example, the mathematical expression of the time-varying meshing stiffness was fit based on the meshing stiffness curve as follows:

$$
k_{S P}(t)=\left\{\begin{array}{l}
3.532 \times 10^{8} \cdots(T \leq t \leq T+0.0002412), \\
1.6774 \times 10^{13}(t-0.0002412)+3.532 \times 10^{8} \cdots(T+0.0002412 \leq t \leq T+0.0004695), \\
7.627 \times 10^{8}-2.106 \times 10^{14}(t-0.000403)^{2} \cdots(T+0.0004695 \leq t \leq T+0.00075905), \\
1.3468 \times 10^{10}-1.6774 \times 10^{13} t \cdots(T+0.00075905 \leq t \leq T+0.00078188), \\
3.532 \times 10^{8} \cdots(T+0.00078188 \leq t \leq T+0.00102) .
\end{array}\right.
$$


TABLE 2: A comparison between the simulation results and the theoretical calculation results.

\begin{tabular}{lccc}
\hline Name & Theoretical values & Simulation values & \\
\hline Meshing force (S-P) & $16080 \mathrm{~N}$ & $16442 \mathrm{~N}$ & Error \\
Meshing force (P-I) & $16080 \mathrm{~N}$ & $16789 \mathrm{~N}$ & $2.2 \%$ \\
Meshing frequency & 980.4 & 980.9 & $4.4 \%$ \\
Sun speed & $1207.5 \mathrm{r} / \mathrm{min}$ & $1207 \mathrm{r} / \mathrm{min}$ & $0.5 \%$ \\
Planetary frame speed & $258 \mathrm{r} / \mathrm{min}$ & $258 \mathrm{r} / \mathrm{min}$ & $0.4 \%$ \\
\hline
\end{tabular}
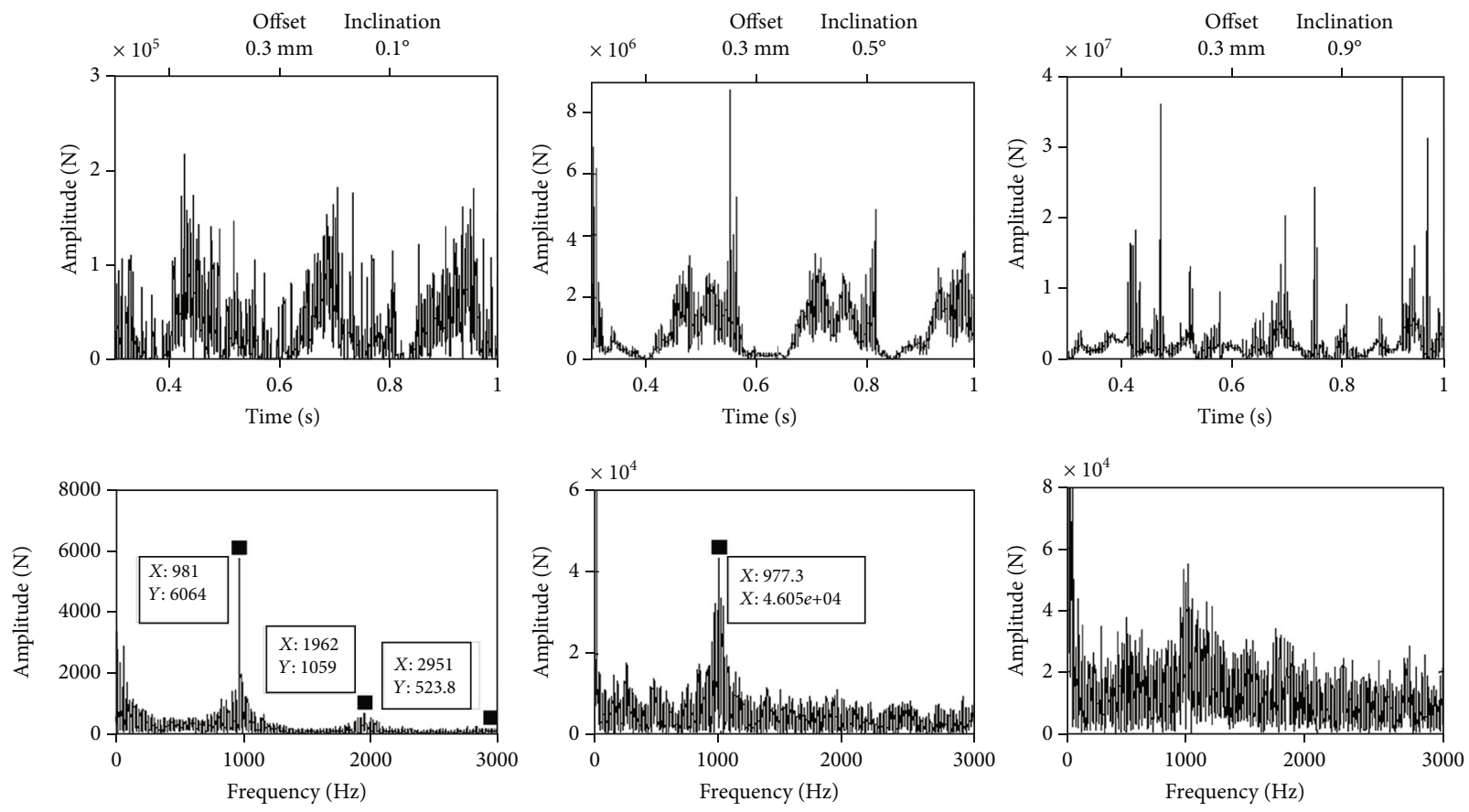

Figure 8: The time domain diagram and frequency spectrum diagram of the meshing force between the sun gear and the planetary gear at different angle inclination positions.

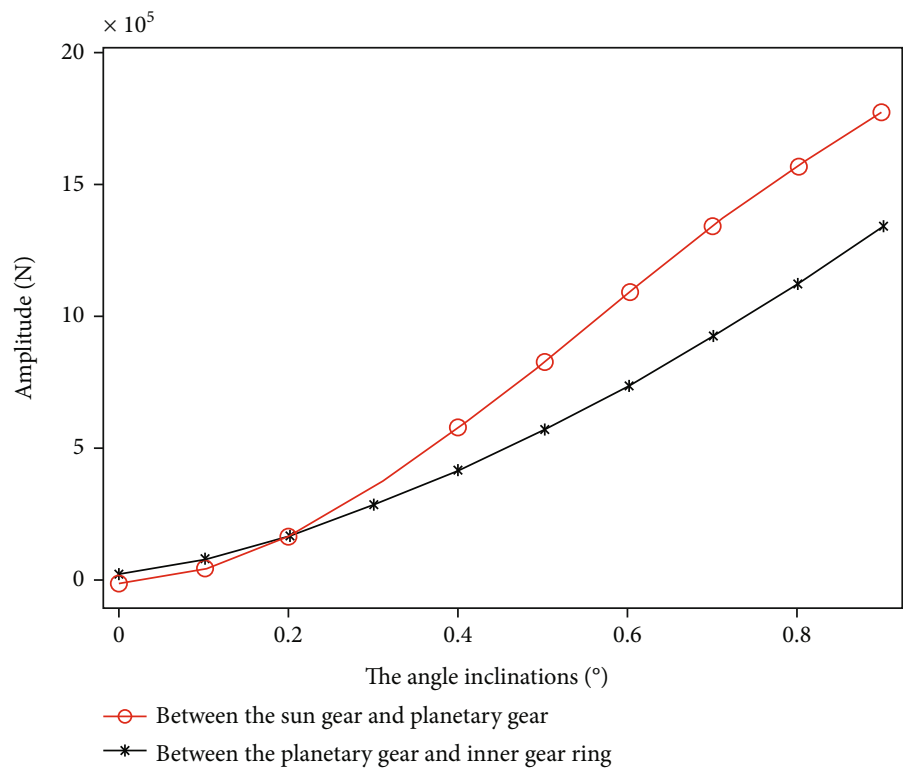

FIGURE 9: The variations in the average meshing force between gear pairs with different inclination angles. 


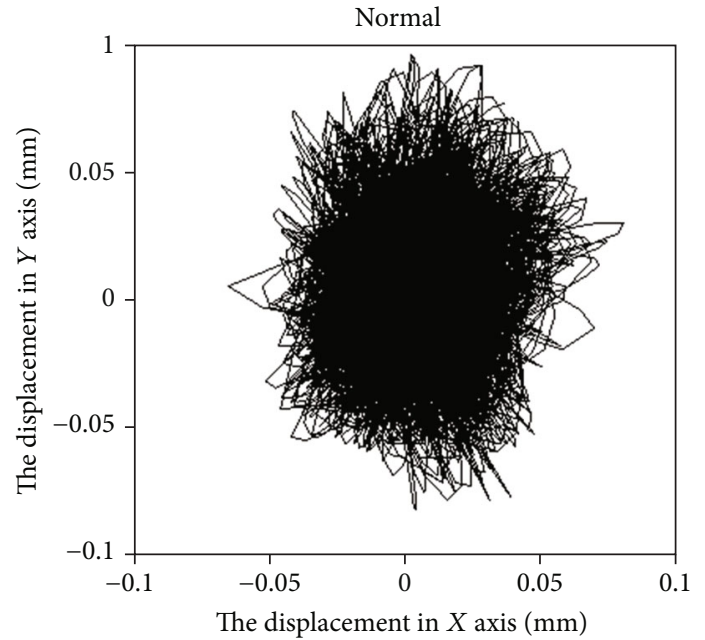

(a)

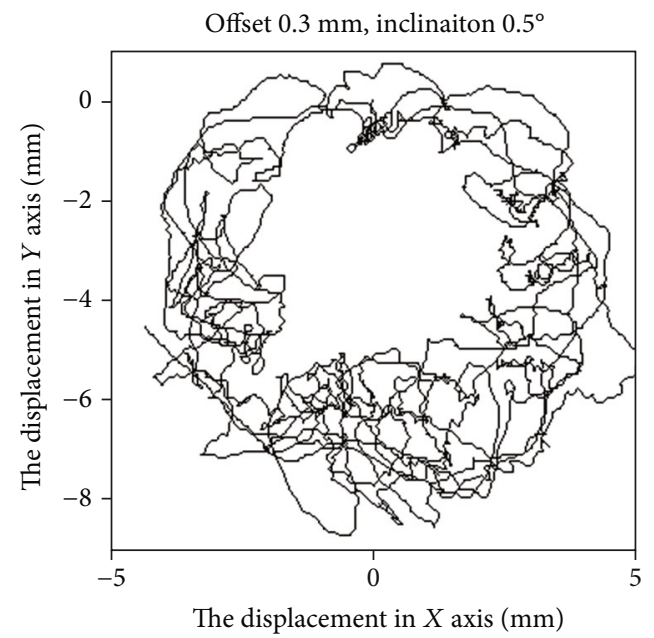

(c)

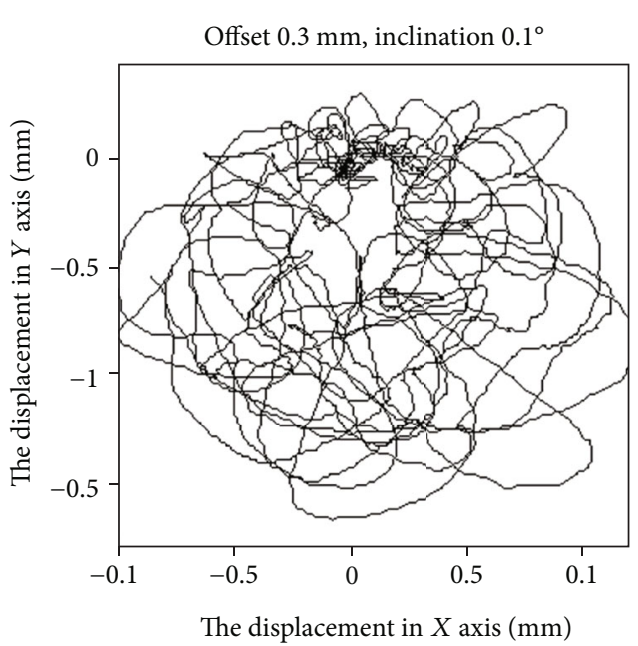

(b)

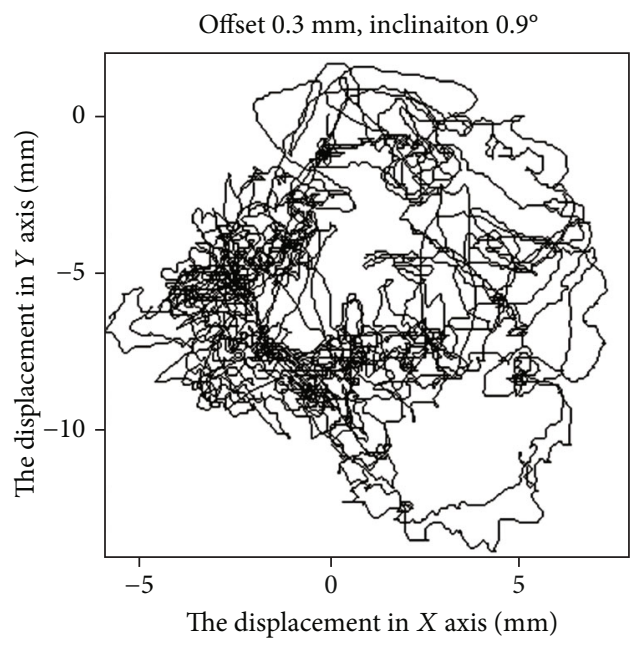

(d)

Figure 10: The shaft center orbit of the sun gear.

Since the piecewise function cannot be directly embedded in the Impact contact function, this paper used the Fourier series expansion to obtain the stiffness expression:

$$
\begin{aligned}
k_{S P_{-} F}(t)= & 7.0015 \times 10^{8}-1.28984 \times 10^{8} \times \cos (6156.8 \mathrm{t}) \\
& +0.09992 \times 10^{8} \times \sin (6156.8 \mathrm{t})-0.29243 \times 10^{8} \\
& \times \cos (12313.7 \mathrm{t})+1.1331 \times 10^{8} \times \sin (12313.7 \mathrm{t}) \\
& -0.28594 \times 10^{8} \times \cos (18470.5 \mathrm{t})+0.66414 \times 10^{8} \\
& \times \sin (18470.5 \mathrm{t})+0.24417 \times 10^{8} \times \cos (24627.4 \mathrm{t}) \\
& +0.13502 \times 10^{8} \times \sin (24627.4 \mathrm{t})-0.07877 \times 10^{8} \\
& \times \cos (30784.3 \mathrm{t}) .
\end{aligned}
$$

Input this expression into the stiffness setting dialog box in the Impact contact function, then, the implantation of the time-varying meshing stiffness between the sun gear and the planetary gear was realized. The implantation of the time- varying meshing stiffness between the other gear pairs can be set as the same procedure.

2.3.4. Model Verification. The simulation conditions were as follows: (a) the main rotor torque was $87,643.66 \mathrm{Nm}$; (b) the input speed of the sun gear was $1,207.5 \mathrm{r} / \mathrm{min}$; (c) a STEP function was used to input the speed and load for the reduction of the impact caused by sudden changes in the speed and load. That is to say, the speed was a step (time, 0,0 , $0.37245 \mathrm{~d}$ ), and the torque load was a step (time, $0,0,0.3$, 87643662), as shown in Figure 7; (d) the simulation time was $2 \mathrm{~s}$, and the number of simulation steps was 8,192 . This study's comparison between the simulation results and the theoretical calculation results is detailed in Table 2.

In Table 2, meshing force (S-P) represents the meshing force between the sun gear and planetary gear, and meshing force (P-I) represents the meshing force between the planetary gear and inner ring gear. It can be found from Table 2 that the simulation values are very close to the theoretical values, which can valid the effectiveness of the simulation model. 


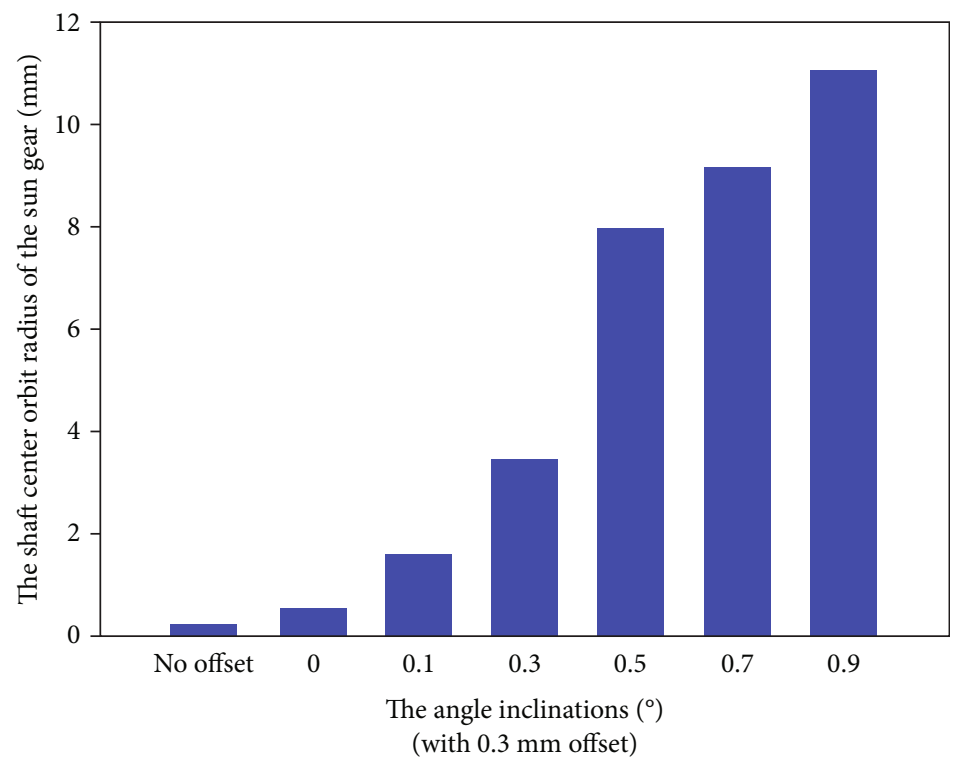

FIGURE 11: The variations in the shaft center orbit radius of the sun gear with different inclination angles.
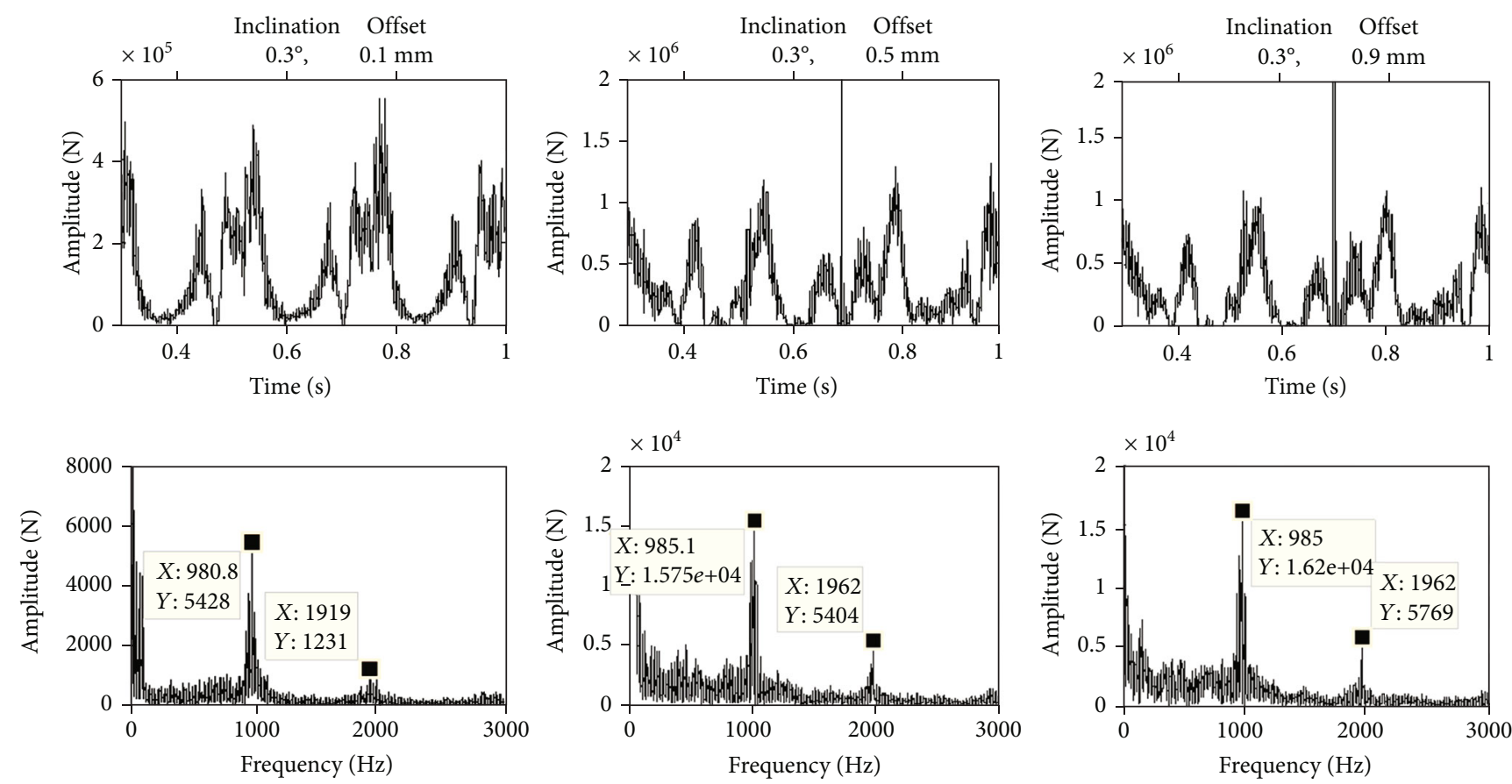

FIgURE 12: The time domain diagram and frequency spectrum diagram of the meshing force of sun gear and planetary gear at different offset positions.

\section{Analysis of the Influencing Effects of the Main Rotor Shaft Position Changes on the Gear Meshing Characteristics}

3.1. Analysis of the Influencing Effects of Different Inclinations of Shafting. It was assumed that the offset of the main rotor shaft was $0.3 \mathrm{~mm}$, and the inclination angles were $0^{\circ}, 0.1^{\circ}, 0.2^{\circ}$, and $\cdots 0.9^{\circ}$, respectively. The simulation models of nine groups of shafting position changes were established, and the corresponding gear meshing stiffness values were input for the simulation analyses. The time domain diagram and frequency spectrum diagram of the meshing force between the sun gear and the planetary gear at different angle inclination positions are shown in Figure 8 . The variations in the average meshing force of the gears with different inclination angles are shown in Figure 9. The shaft center orbit of the sun gear is shown in Figure 10, and the variations of the shaft center orbit radius of the sun gear with the different inclination angles are detailed in Figure 11. 


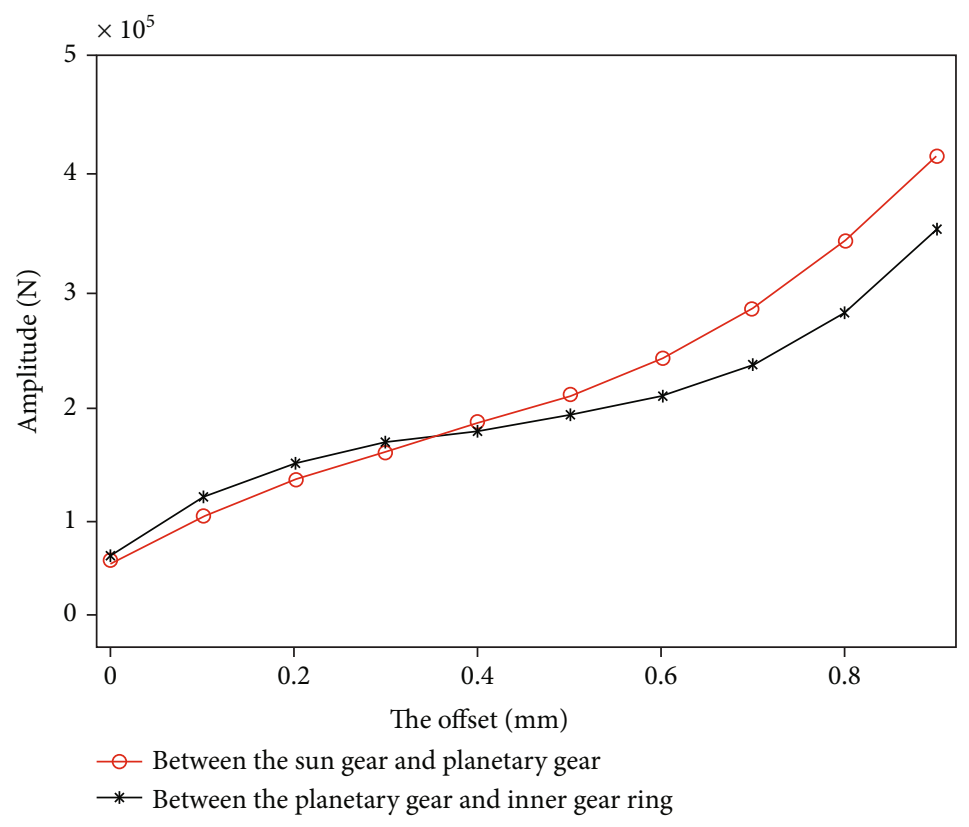

Figure 13: The variations in the average meshing force of the gears with different offsets.

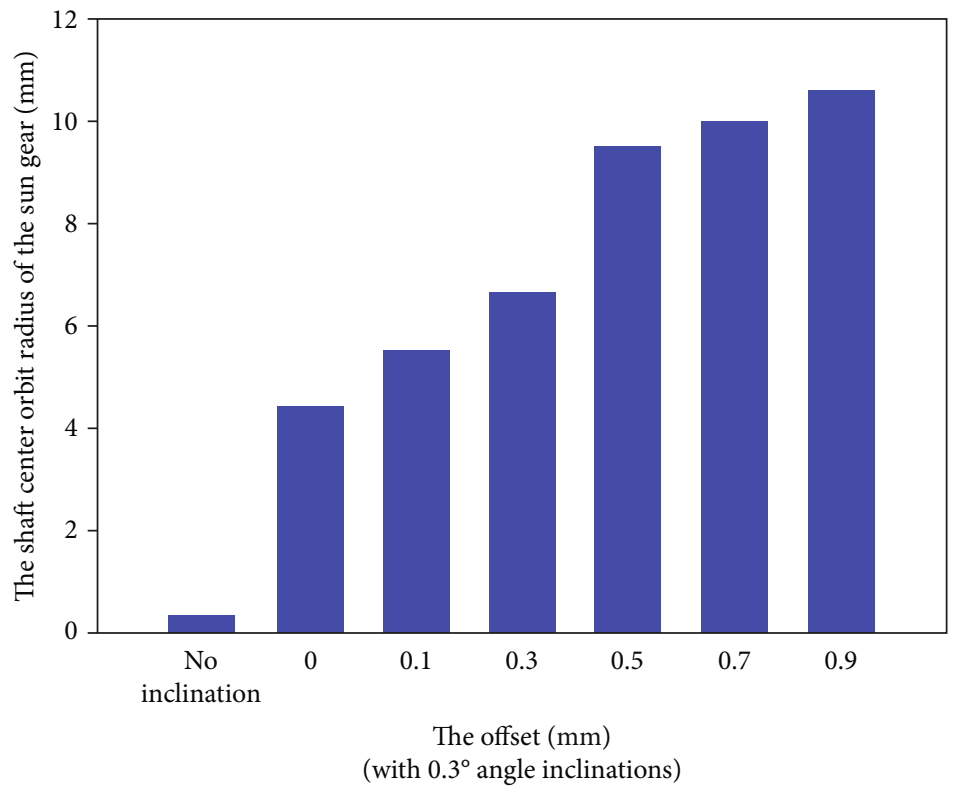

Figure 14: The variations in the shaft center orbit radius of the sun gear with different offsets.

It can be seen from Figure 8, when the tilt positions of the main rotor shafts of the helicopter changed, the meshing force of the gears in the planetary gear train had displayed obvious changes in time and frequency domain. In addition, with the changes in the shafting tilt positions, obvious side frequency signal appeared around the peak of the meshing frequency in the spectrum. However, it was observed that with the continuous increases in the tilt positions, the peak became gradually submerged. Figure 9 indicates that the average meshing force increased with the increases in the angle inclinations, and the meshing force between the sun gear and the planetary gear increased at a faster rate than that between the planetary gear and the inner ring gear. From Figure 10, it can be seen, with the increases in the angle inclinations, the shaft center orbit of the sun gear moves downward as a whole. Figure 11 indicates that the shaft center orbit radius of the sun gear increased with the increases in the inclination angles.

3.2. Analysis of the Influencing Effects of Different Offsets of Shafting. By assuming that the inclination angle of the main rotor shaft was $0.3^{\circ}$ and the offsets were $0 \mathrm{~mm}, 0.1 \mathrm{~mm}$, $0.2 \mathrm{~mm}$, and $\cdots 0.9 \mathrm{~mm}$, respectively, the simulation models of nine groups of shafting position changes were established 
in this study. The corresponding gear meshing stiffness values were then input for the simulation analyses. This study's time domain diagram and frequency spectrum diagram of the meshing force of sun gear and planetary gear at different offset positions are shown in Figure 12. The variations in the average meshing force of the gears with offsets are detailed in Figure 13, and the variations of the shaft center orbit radius of the sun gear with offsets are shown in Figure 14.

As detailed in Figure 12, when the offset positions of the helicopter's main rotor shaft changed, there are obvious first and second doubling frequencies in the spectrum. In addition to the increase in amplitude, the meshing force of the gears in the planetary gear train had displayed small changes in time and frequency domain. Figure 13 indicates the average meshing force of the gears increased with the increases in the offset. Furthermore, the increasing trend of the meshing force between the sun gear and the planetary gear was found to be similar to that between the planetary gear and the inner ring gear. From Figure 14, it can be seen that the shaft center orbit radius of the sun gear increased with the increases in the offsets. However, the influencing effects were smaller than the changes of the angular tilt positions.

\section{Conclusions}

In this research investigation, the gear meshing characteristics of the main transmission planetary gear train of helicopters when the position of the planetary carrier (for example, the main rotor shaft) changed were examined. This study mainly focused on the changes in the gear meshing force with the different tilt positions and offset positions of the main rotor shaft. The conclusions reached from this study's research results were as follows:

(1) The average meshing force of the gears increases with the increases in the angle inclination, and the meshing force between the sun gear and the planetary gear increased at a faster rate than that between the planetary gear and the inner ring gear. It was observed that under the conditions of the changes in shafting tilt position, obvious side frequency signal appeared around the peak of the meshing frequency in the spectrum

(2) The average meshing force of the gears increased with the increases in the offsets, and the increasing trend of the meshing force between the sun gear and the planetary gear was similar to that between the planetary gear and the inner ring gear. It was found that when the shafting offset positions changed, there were obvious first and second doubling frequency in the spectrum

(3) The shaft center orbit radius of the sun gear increased with the increases in the shafting position changes, and the changes in the angular tilt positions had a greater influence on the mass center orbit radius of the sun gear than the changes in the offset positions
The revealed dynamic response characteristics of the helicopter shaft systems under changes in the relative position could provide a theoretical basis for the failure mechanism analysis and the operational status monitoring of the helicopter transmission. Further dynamic response analysis to establish the mapping relationship between dynamic response characteristics and failure evolution process is one of the important research works in the future.

\section{Data Availability}

Data is available on request.

\section{Conflicts of Interest}

The authors declare that they have no conflicts of interest.

\section{Acknowledgments}

This work was supported by the National Natural Science Foundation of China (Grant nos. 11872022) and the National Aeronautical Science Foundation of China (Grant nos. 20200033116001).

\section{References}

[1] UH-60A STUDENT HANDOUT, UH-60A Powertrain/ Rotor System, United States Army Aviation Warfighting Center, Fort Rucker, Alabama, 2008.

[2] P. Paschinger and M. Weigand, "Study on possible solutions of a compound-split transmission system for the UH-60 helicopter," Mechanism and Machine Theory, vol. 129, pp. 17-35, 2018.

[3] E. Faris, G. Matthew, and M. David, "Planetary bearing defect detection in a commercial helicopter main gearbox with vibration and emission acoustic," Structural Health Monitoring, vol. 17, no. 5, pp. 1192-1212, 2018.

[4] L. Zhou, F. Duan, D. Mba, W. Wang, and S. Ojolo, "Using frequency domain analysis techniques for diagnosis of planetary bearing defect in a CH-46E helicopter aft gearbox," Engineering Failure Analysis, vol. 92, pp. 71-83, 2018.

[5] P. D. Samuel and D. J. Pines, "A review of vibration-based techniques for helicopter transmission diagnostics," Journal of Sound and Vibration, vol. 282, no. 1-2, pp. 475-508, 2005.

[6] P. Knight and J. Cook, "Intelligent management of helicopter health and usage management systems data," Proceedings of the Institution of Mechanical Engineers Part G-Journal of Aerospace Engineering, vol. 219, no. 6, pp. 507-524, 2005.

[7] S. Canfei, Y. Wang, and S. Guodong, "A multi-criteria fusion feature selection algorithm for fault diagnosis of helicopter planetary gear train," Chinese Journal of Aeronautics, vol. 33, no. 5, pp. 1549-1561, 2020.

[8] C. Zhongsheng and Y. Yongmin, "Fault diagnostics of helicopter gearboxes based on multi-sensor mixtured hidden Markov models," Journal of vibration and acoustics, vol. 134, no. 3, article 031010, 2012.

[9] F. Elasha, X. Li, D. Mba, A. Ogundare, and S. Ojolo, "A novel condition indicator for bearing fault detection within helicopter transmission," Journal of Vibration Engineering \& Technologies, vol. 9, no. 2, pp. 215-224, 2021. 
[10] L. Zhou, F. Duan, M. Corsar, F. Elasha, and D. Mba, "A study on helicopter main gearbox planetary bearing fault diagnosis," Applied Acoustics, vol. 147, no. s1, pp. 4-14, 2019.

[11] D. Nedelko, A. Urbahs, V. Turko, M. Urbaha, K. Carjova, and P. Nagaraj, "Assessment of the limits of signs of health and usage monitoring system for helicopter transmission," Procedia Computer Science, vol. 149, pp. 252-257, 2019.

[12] N. Roh, S. Oh, and D. Park, "Aerodynamic characteristics of helicopter with ducted fan tail rotor in hover under low-speed crosswind," International Journal of Aerospace Engineering, vol. 2020, Article ID 7059209, 14 pages, 2020.

[13] F. Chenxi, Z. Ning, and Y. Zhao, "Load sharing multiobjective optimization design of a split torque helicopter transmission," Mathematical Problems in Engineering, vol. 2015, Article ID 381010, 15 pages, 2015.

[14] K. Lyu, X. Tan, G. Liu, and C. Zhao, "Sensor selection of helicopter transmission systems based on physical model and sensitivity analysis," Chinese Journal of Aeronautics, vol. 27, no. 3, pp. 643-654, 2014.

[15] Z. Wei and L. An, "Dynamic analysis on single-rotor multiinput helicopter main gearbox related with structural parameters," Journal of Low Frequency Noise Vibration and Active Control, vol. 40, no. 1, pp. 181-294, 2021.

[16] Y. Chen, R. Zhu, G. Jin, Y. Xiong, J. Gao, and M. Liao, “A new mathematical modeling method for four-stage helicopter main gearbox and dynamic response optimization," Complexity, vol. 2019, Article ID 5274712, 13 pages, 2019.

[17] J. Liu, R. Pang, S. Ding, and X. Li, "Vibration analysis of a planetary gear with the flexible ring and planet bearing fault," Measurement, vol. 165, p. 108100, 2020.

[18] L. Zhang, Y. Wang, K. Wu, R. Sheng, and Q. Huang, "Dynamic modeling and vibration characteristics of a two-stage closedform planetary gear train," Mechanism and Machine Theory, vol. 97, pp. 12-28, 2016.

[19] X. LIANG, M. J. ZUO, and M. PANDEY, “Analytically evaluating the influence of crack on the mesh stiffness of a planetary gear set," Mechanism and Machine Theory, vol. 76, no. 1, pp. 20-38, 2014.

[20] K. Chen, Y. Huangfu, H. Ma, Z. Xu, X. Li, and B. Wen, "Calculation of mesh stiffness of spur gears considering complex foundation types and crack propagation paths," Mechanical Systems and Signal Processing, vol. 130, pp. 273-292, 2019.

[21] Y. Lei, Z. Liu, D. Wang, X. Yang, H. Liu, and J. Lin, “A probability distribution model of tooth pits for evaluating timevarying mesh stiffness of pitting gears," Mechanical Systems and Signal Processing, vol. 106, pp. 355-366, 2018.

[22] J. Wei, A. Zhang, L. Shi, and D. Qin, "Modeling and dynamic characteristics of planetary gear transmission in non-inertial system of aerospace environment," ASME Journal of Mechanical Design, vol. 142, no. 3, article 031103, 2020.

[23] H. Han, Z. Zhao, H. Tian, H. Ma, Y. Yang, and X. Li, "Fault feature analysis of planetary gear set influenced by cracked gear tooth and pass effect of the planet gears," Engineering Failure Analysis, vol. 121, p. 105162, 2021.

[24] R. G. Parker and X. Wu, "Vibration modes of planetary gears with unequally spaced planets and an elastic ring gear," Journal of Sound and Vibration, vol. 329, no. 11, pp. 2265-2275, 2010.

[25] C. Xun, X. Long, and H. Hua, "Effects of random tooth profile errors on the dynamic behaviors of planetary gears," Journal of Sound and Vibration, vol. 415, pp. 91-110, 2018.
[26] L. Xianzeng, Y. Yang, and Z. Jun, "Effects of tooth-crackinduced mesh stiffness on fault signals of a planetary gear train," Procedia Computer Science, vol. 109, pp. 785-792, 2017.

[27] A. Mbarek, A. Hammami, A. F. Del Rincon, F. Chaari, F. V. Rueda, and M. Haddar, "Effect of load and meshing stiffness variation on modal properties of planetary gear," Applied Acoustics, vol. 147, pp. 32-43, 2019.

[28] L. Ryali and D. Talbot, "A dynamic load distribution model of planetary gear sets," Mechanism and Machine Theory, vol. 158, article 104229, 2021.

[29] G. Shen, D. Xiang, K. Zhu, L. Jiang, Y. Shen, and Y. Li, “Fatigue failure mechanism of planetary gear train for wind turbine gearbox," Engineering Failure Analysis, vol. 87, pp. 96-110, 2018.

[30] L. Xianzeng, Y. Yang, and Z. Jun, "Resultant vibration signal model based fault diagnosis of a single stage planetary gear train with an incipient tooth crack on the sun gear," Renewable Energy, vol. 122, pp. 65-79, 2018. 